Original paper

\title{
Sexual reproduction of soft coral, Scleronephthya gracillimum, (Alcyonacea: Nephtheidae) based on long-term collection from Jejudo Island, Korea
}

\author{
Sung Jin HWANG and Jun Im SONG*
}

Division of EcoScience, College of Natural Sciences, Ewha Womans University, Seoul, Republic of Korea

* Corresponding author: J.I. Song

E-mail: jisong@ewha.ac.kr

Communicated by Makoto Tsuchiya

\begin{abstract}
The soft coral Scleronephthya gracillimum (Alcyonacea: Octocorallia), a member of family Nephtheidae, is abundant in the southern part of Jejudo Island, Korea. To examine the sexual reproductive pattern, monthly collections and histological studies were conducted from June 2003 to October 2007. The sexual reproductive pattern of the genus Scleronephthya was described for the first time in the present study, which established that $S$. gracillimum is a gonochoric broadcaster, with the sex ratio of $1: 1$. The gametogenic cycle was annual, and a difference between female and male colonies was apparent, with biorhythms of 12 and 5-7 months respectively. Gametogenesis and spawning are related to seasonal factors such as seawater temperature and algal blooms. Actual spawning event occurred, and others may have taken place, when seawater temperature attained an annual peak between August and September. The actual spawning occurred in the field at 10 a.m. on September 3, 2006, 4 days before the full moon.
\end{abstract}

Keywords sexual reproduction, gametogenesis, Scleronephthya gracillimum, soft coral, Anthozoa

\section{Introduction}

Soft corals, of the order Alcyonacea, are ecologically important sessile members of coral reef communities, and are distributed from tropical to temperate regions. These corals have three modes of sexual reproduction, namely the broadcasting of gametes, internal brooding, and external surface brooding involving planulae (Farrant 1986; Benayahu et al. 1990; Benayahu 1991; Cordes et al. 2001). The reproductive patterns of alcyonaceans are summarized in Table 1. The reproductive mode of soft corals varies among different family groups; gonochorism is generally dominant in soft coral species, although a few species are hermaphroditic (Sebens 1983; Benayahu et al. 1990; Achituv et al. 1992; McFadden et al. 2001; McFadden and Hochberg 2003; Choi and Song 2007; Hwang and Song 2007). Most species belonging to the family Alcyoniidae employ the broadcast mode of reproduction. In the family Xeniidae, by contrast, only brooding behavior has been described, although the examination about reproductive mode has not been finished yet.

Generally, the production and development of gametes is similar in most soft corals. Gametes are formed in the mesenteries, and then move into the gastrovascular cavity, where they mature (Benayahu 1991; McFadden and Hochberg 2003). Broadcast spawning events of corals are 
Table 1 Reproductive pattern reported in the literature on Alcyonacea

\begin{tabular}{|c|c|c|c|c|c|c|c|c|c|c|}
\hline \multirow{2}{*}{ Taxa } & \multirow{2}{*}{$\begin{array}{l}\text { Number } \\
\text { of species }\end{array}$} & \multicolumn{4}{|c|}{ Sexuality } & \multicolumn{4}{|c|}{ Mode of reproduction } & \multirow{2}{*}{ References } \\
\hline & & $\mathrm{G}$ & $\mathrm{H}$ & $\mathrm{G} / \mathrm{H}$ & $\mathrm{P}$ & BS & $\mathrm{EB}$ & IB & $\mathrm{U}$ & \\
\hline Alcyoniidae & 37 & 35 & 1 & - & 1 & 26 & 2 & 7 & 2 & $1,3,4,7,8,9,10,11$ \\
\hline Alcyonium & 11 & 9 & 1 & - & 1 & 5 & 1 & 4 & 1 & $1,3,8,9$ \\
\hline Anthomastus & 1 & 1 & - & - & - & - & - & 1 & - & 7 \\
\hline Cladiella & 1 & 1 & - & - & - & 1 & - & - & - & 4 \\
\hline Discophyton & 1 & 1 & - & - & - & - & - & 1 & - & 9 \\
\hline Lobophytum & 7 & 7 & - & - & - & 7 & - & - & - & 3,11 \\
\hline Parerythropodium & 1 & 1 & - & - & - & - & 1 & - & - & 3 \\
\hline Sarcophyton & 4 & 4 & - & - & - & 4 & - & - & - & 3,10 \\
\hline Sinularia & 9 & 9 & - & - & - & 9 & - & - & - & 3 \\
\hline Thrombophyton & 2 & 2 & - & - & - & - & - & 1 & 1 & 9 \\
\hline Nephtheidae & 6 & 6 & - & - & - & 3 & 1 & 2 & - & $2,3,6,12,13$ \\
\hline Litophyton & 1 & 1 & - & - & - & - & - & 1 & - & 3 \\
\hline Scleronephthya & 1 & 1 & & & & 1 & & & & present \\
\hline Dendronephthya & 3 & 3 & - & - & - & 2 & - & 1 & - & $6,12,13$ \\
\hline Capnella & 1 & 1 & - & - & - & - & 1 & - & - & 2 \\
\hline Xeniidae & 24 & 18 & 5 & 1 & - & - & 1 & 16 & 7 & $3,4,5$ \\
\hline Xenia & 15 & 12 & 3 & - & - & - & - & 10 & 5 & $3,4,5$ \\
\hline Heteroxenia & 4 & 1 & 2 & 1 & - & - & - & 4 & - & 3 \\
\hline Anthelia & 2 & 2 & - & - & - & - & - & 1 & 1 & 3,4 \\
\hline Sympodium & 1 & 1 & - & - & - & - & - & 1 & - & 3,4 \\
\hline Efflatounaria & 1 & 1 & - & - & - & - & 1 & - & - & 3 \\
\hline Cespitularia & 1 & 1 & - & - & - & - & - & - & 1 & 4 \\
\hline
\end{tabular}

References: (1) Sebens 1983, (2) Farrant 1986, (3) Benayahu et al. 1990, (4) Benayahu 1991, (5) Achituv et al. 1992, (6) Dahan and Benayahu 1997, (7) Cordes et al. 2001, (8) McFadden et al. 2001, (9) McFadden and Hochberg 2003, (10) Schleyer et al. 2004, (11) Fan et al. 2005, (12) Choi and Song 2007, (13) Hwang and Song 2007.

$B S$ broadcast spawner, $E B$ external brooder, $G$ gonochoric, $H$, hermaphroditic $G / H$ gonochoric or hermaphroditic, $I B$ internal brooder, $P$ parthenogenetic, $U$ unknown.

usually synchronous and seasonal, although only a low level of synchrony is apparent in temperate species (Harrison et al. 1984; Benayahu and Loya 1986; Harrison and Wallace 1990; Benayahu 1991; Ben-David-Zaslow et al. 1999; Kapela and Lasker 1999; Cordes et al. 2001; Schleyer et al. 2004).

Limited information is available regarding the sexual reproduction of Nephtheidae, compared with that on Alcyoniidae and Xeniidae. Also, most studies on reproduction have been conducted in only a few geographical regions, mainly the Red Sea, the Australian Great Barrier Reef, and the Northeastern Pacific Ocean (Benayahu et al. 1990; Benayahu 1991; McFadden et al. 2001; McFadden and Hochberg 2003). The genus Scleronephthya, a member of the family Nephtheidae, inhabits tropical-to- temperate regions (Fabricius and Alderslade 2001), and only one species, Scleronephthya gracillimum (Kükenthal, 1906), has been reported in Korean waters to date (Song 1976). In the present report, reproductive features such as sexuality, reproductive mode, gametogenesis, and the reproductive cycle, are described for $S$. gracillimum for the first time.

\section{Materials and methods}

\section{Collection of specimens}

Colonies of $S$. gracillimum are abundant on the south coast of Jejudo Island (Fig. 1) in Korea, located in the temperate zone but with a somewhat subtropical climate 


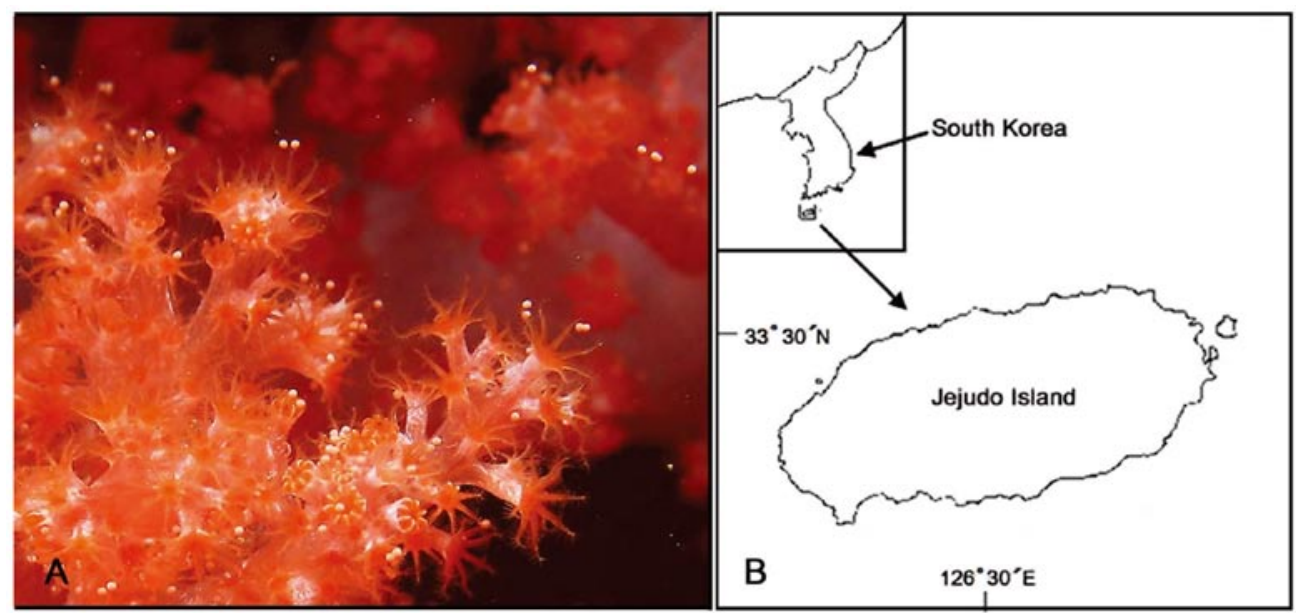

Fig. 1 Colonies of Scleronephthya gracillimum and map of the study site. A Colonies spawned eggs in the field on September 3, 2006. B Jejudo Island is located in the most southern part of Korea

because the coast is affected by the Tsushima Warm Current branching from the Kuroshio Current. Colonies live mainly on the vertical surfaces of rocks in our study area, where seawater temperatures range from $14-26^{\circ} \mathrm{C}$ depending on season. Long $(5-6 \mathrm{~cm})$ fragments were collected from randomly selected colonies (height $>30$ $\mathrm{cm}$ ) located at depths of $10 \mathrm{~m}$ and $30 \mathrm{~m}$ by researchers wearing SCUBA apparatus, between June 2003 and October 2007. After collection, samples were anesthetized with menthol for 4-6 hours, and were then fixed in 4-5\% (v/v) neutral formalin, diluted with seawater, for 24 hours. Finally, samples were transferred into $70 \%(\mathrm{v} / \mathrm{v})$ ethanol for preservation.

\section{Dissection and histology}

Each preserved specimen was examined under a Zeiss (Semi SV-6) stereomicroscope to determine the sexuality of each colony and the external features of gametes. To investigate gametogenic cycles, the longest and shortest axes of about 30 gametes from each colony were measured using an image analyzer (Motic Image Plus 2.0 instrument) on a monthly basis, and an average axis length was calculated. Seawater temperature near the collection site was recorded monthly by Korea Hydrographic and Oceanographic Administration (KHOA) during the entire study period.

Histology was employed to identify gametogenic stages and the reproductive mode. Tissues $0.5-1.0 \mathrm{~cm}$ in both length and width were cut from preserved specimens, decalcified in $10 \%(\mathrm{w} / \mathrm{v})$ EDTA solution for 5 days, and then dehydrated in a graded series of ethanol baths. Dehydrated tissues were cleared with a mixture of xylene and ethanol, embedded in paraffin, and cut into sections of $10 \mu \mathrm{m}$ thick using a microtome. Serial sections were stained with Harris hematoxylin and eosin Y and mounted using Shandon Synthetic Mountant (Thermo). Sections were observed under an Olympus BH-2 microscope.

\section{Images and analysis}

Photographs of living colonies in water were taken with an Olympus 5060-WZ digital camera fitted with an Underwater Patima 7070 Housing, and all images of gametes and histological sections were obtained using the same camera attached to stereomicroscopes (Semi SV-6 and SV-11 instruments) or a light microscope (Olympus BH2 instrument). The sex ratio was determined by counting the numbers of female and male colonies from June to October throughout study periods, when oocytes and spermaries were observed together. The $\chi^{2}$ goodness-of-fit test was used to test for deviation from a 1:1 sex ratio, using SPSS (version 12). 


\section{Results}

\section{Sexuality and sex ratio}

All $S$. gracillimum colonies analyzed microscopically and histologically were determined to be gonochoric. Among the total of 269 colonies examined during the entire study period, 131 were female, 79 male, and 59 contained small or no gametes. Female colonies were significantly more abundant than male colonies, with a sex ratio of 1.76:1. However, male colonies were observed only from late spring or early summer to fall. On the other hand, female colonies were present throughout the year. Thus, only 85 female and 75 male colonies obtained between June and October were used to calculate the precise sex ratio, excluding possible male colonies with small or no gametes. This sex ratio was not significantly different from 1:1 $\left(\chi^{2}=90.625, d f=1, P=0.429\right)$.

\section{Gametogenesis (gonadal development)}

Development of gametes in S. gracillimum was similar to that in other alcyonaceans; gametes originated from gastrodermal mesenteries within the polyp cavity. Immature gametes gradually moved into the gastrovascular cavity, being initially connected to the mesenteries by pedicles, and then detached from the mesenteries as they matured.

Oogenesis. Oocyte was easily defined microscopically by the presence of a transparent follicular layer and a prominent nucleus with a single nucleolus. Spherical oocytes tended to change from transparent to cream in color, and then to vivid orange, as they matured. The development of oocytes was classified into five stages, depending on maturity, as shown in Table 2.
The earliest oocytes, in stage I, were in the mesoglea of mesenteries and were smaller than $50 \mu \mathrm{m}$ in diameter, with an average size of $39.2 \pm 8.1 \mu \mathrm{m}$ (mean \pm SD, $n=98)$ (Fig. 2a). These oocytes contained large distinct nuclei, and were transparent because of a lack of cytoplasm. As the oocytes grew into stage II, the color changed to cream as a result of accumulation of cytoplasm, and one-sided nuclei were seen. At this stage, oocytes were observed in the gastrovascular cavity and were individually connected to mesenteries by pedicles (Fig. 2a). The diameter of oocytes ranged from 51-149 $\mu \mathrm{m}$ with a mean value of $112.2 \pm 24.5 \mu \mathrm{m}(\mathrm{n}=1,515)$. At stage III, vitellogenesis (yolk synthesis) commenced, and yolk bodies accumulated around the nuclei of oocytes, resulting in a color change from cream to light orange. The maturing oocytes became detached from the mesenteries, entering into a cavity covered by follicular layers (Fig. 2b); the oocytes ranged in diameter from $150-199 \mu \mathrm{m}$, with a mean of $169.8 \pm$ $13.5 \mu \mathrm{m}(\mathrm{n}=590)$. In stage IV, yolk bodies were continuously synthesized, and spread throughout the entire oocyte (Fig. 2c), so that the color of oocytes became gradually deeper. Late vitellogenic oocytes ranged from 200-299 $\mu \mathrm{m}$ in diameter, with a mean of $255.2 \pm 29.8 \mu \mathrm{m}$ $(n=464)$. Fully mature oocytes, in stage V, were vivid dark orange in color and were over $300 \mu \mathrm{m}$ in diameter, with a maximum of $473 \mu \mathrm{m}$ and an average of $346.2 \pm$ $35.0 \mu \mathrm{m}(\mathrm{n}=370)$ (Fig. 2d). These oocytes were covered with a well-developed follicular layer. Embryos and planulae were not observed when oocytes were at this stage within the cavity.

Spermatogenesis. The development of spermaries was classified into four stages depending on maturity, as shown in Table 2. Spermaries at the earliest stage were embedded

Table 2 Range and mean diameter of gametes, which depends of stages (n number of gametes at each stage)

\begin{tabular}{|c|c|c|c|c|c|c|}
\hline \multirow{2}{*}{ Stage } & \multicolumn{3}{|c|}{ Oocytes } & \multicolumn{3}{|c|}{ Spermaries } \\
\hline & Range $(\mu \mathrm{m})$ & Mean $\pm \mathrm{SD}(\mu \mathrm{m})$ & $\mathrm{n}$ & Range $(\mu \mathrm{m})$ & Mean $\pm \mathrm{SD}(\mu \mathrm{m})$ & $\mathrm{n}$ \\
\hline I & $\leq 50$ & $39.2 \pm 8.1$ & 98 & $\leq 50$ & $43.2 \pm 5.3$ & 52 \\
\hline II & $51-149$ & $112.2 \pm 24.5$ & 1515 & $51-99$ & $76.9 \pm 14.1$ & 350 \\
\hline III & $150-199$ & $169.8 \pm 13.5$ & 590 & $100-174$ & $134.3 \pm 20.2$ & 1047 \\
\hline IV & $200-299$ & $255.2 \pm 29.8$ & 464 & $\geq 175$ & $203.0 \pm 23.4$ & 281 \\
\hline V & $\geq 300$ & $346.2 \pm 35.0$ & 370 & & & \\
\hline
\end{tabular}




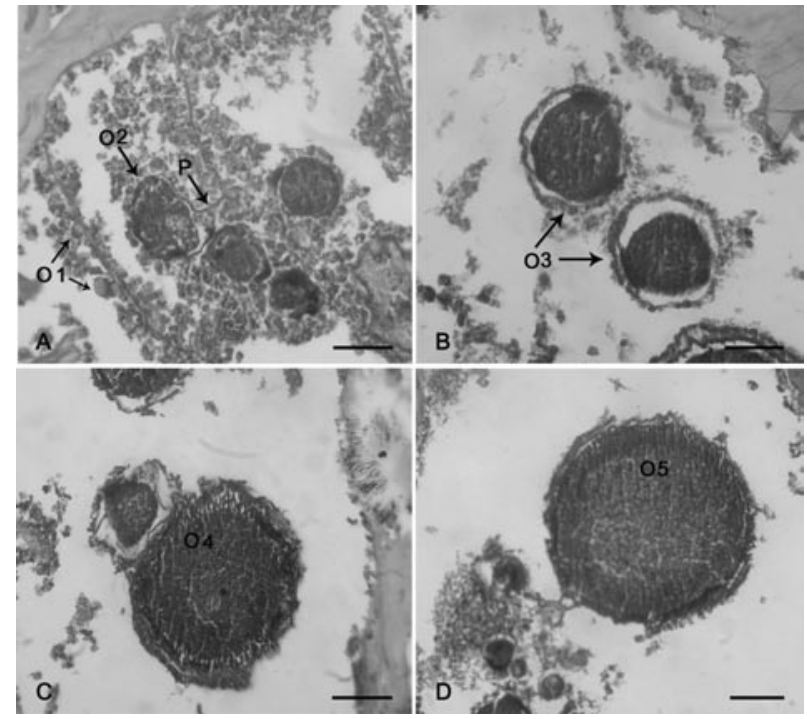

Fig. 2 Development of oocytes. A Stage I oocytes embedded in the mesentery and stage II oocyte connected to mesentery by pedicle. B Stage III oocytes enveloped with follicular layers. C Stage IV oocyte contained numerous yolk bodies. D Fully matured stage V oocyte. The scale bar $=100 \mu \mathrm{m}, O 1$ stage I oocyte, $O 2$ stage II oocyte, $O 3$ stage III oocyte, $O 4$ stage IV oocyte, $O 5$ stage $\mathrm{V}$ oocyte, $P$ pedicle

in mesenteries containing clusters of spermatogonia, and the boundaries of the spermaries were unclear (Fig. 3a). Stage I spermaries were spherical and were less than $50 \mu \mathrm{m}$ in diameter, with a mean of $43.2 \pm 5.3 \mu \mathrm{m}(\mathrm{n}=52)$. In stage II, spermaries were filled with developing spermatocytes and moved into the cavity, where they remain attached to the mesenteries by pedicles (Fig. 3b). These opaque spermaries had distinct boundaries and ranged in diameter from 51-99 $\mu \mathrm{m}$, with a mean of $76.9 \pm 14.1 \mu \mathrm{m}$ $(n=350)$. In stage III, spermatocytes were arranged at the periphery of spermaries, resulting in hollow centers (Fig. 3b, c), and began to develop into spermatids. The spermaries changed from opaque to tinted cream in color as spermatids accumulated. The diameter of spermaries ranged from $100^{-174} \mu \mathrm{m}$, with a mean of $134.3 \pm 20.2 \mu \mathrm{m}$ $(n=1,047)$. In stage IV, spermaries attained their full size and were completely mature, with diameters in excess of $175 \mu \mathrm{m}$, with a maximum of $281 \mu \mathrm{m}$ and a mean of 203.0 $\pm 23.4 \mu \mathrm{m}(\mathrm{n}=281)$. Late in this stage, spermatids began to metamorphose into spermatozoa in these cream-colored spermaries. Tails began to be displayed, and the spermatozoa formed a parallel array. A convolution of sper-

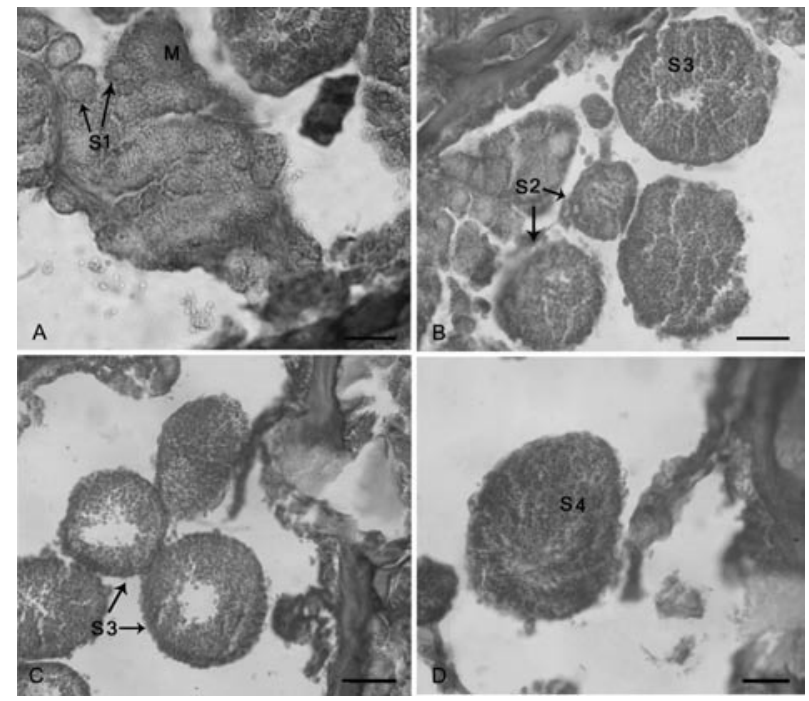

Fig. 3 Development of spermaries. A Stage I spermaries embedded in the mesentery containing clusters of spermatogonia. B Stage II and stage III spermaries filled with spermatocytes. C Spermatocytes arranged at the periphery of stage III spermaries. D Stage IV spermary with a convolution of spermatozoa at the on-side. The scale bar $=50 \mu \mathrm{m}, M$ mesentery, $S 1$ stage I spermary, $S 2$ stage II spermary, $S 3$ stage III spermary $S 4$ stage IV spermary

matozoa at the on-side of spermaries was observed before sperm was released (Fig. 3d).

\section{Gametogenic cycle and spawning}

Annual reproductive cycle (oogenic and spermatogenic cycle). S. gracillimum showed a single annual reproductive cycle, with a clear difference between females and males. Whereas spermaries were detected only between June and December in 2003, June and October in 2004, April and August in 2005, June and October in 2006, and May and October in 2007, oocytes were observed throughout the year, except when collections were not possible.

In females, oocytes of stages I and II were found throughout most of the study period, although their relative frequency changed with the season (Fig. 4). In June 2003, the sum of the relative frequencies of these two stages was comparatively high at 0.8 , and this sum subsequently dropped sharply, to under 0.1 , between July and August. By late September, the two stages of oocytes recorded the highest combined frequency of 1.0, and this high frequency was continuously maintained until the following May, with an average of $0.9( \pm 0.10, n=9)$. A 

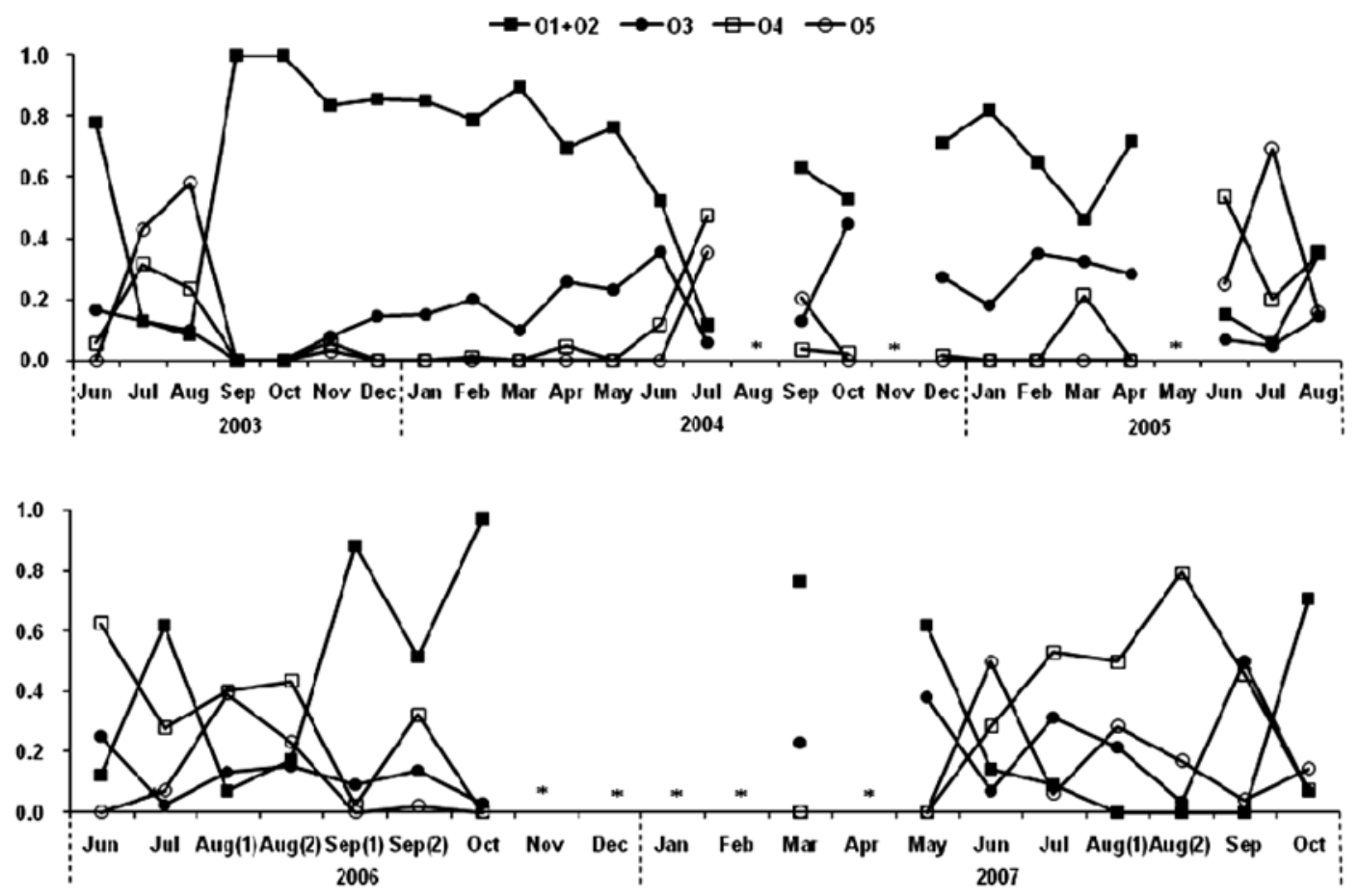

Fig. 4 Monthly frequency of each oogenic stage from June 2003 to October 2007 ( $\mathrm{n}=3037$ oocytes). O1 stage I oocytes, $O 2$ stage II oocytes, $O 3$ stage III oocytes, $O 4$ stage IV oocytes, $O 5$ stage V oocytes, * month with no collection

similar pattern, with small fluctuations, appeared in successive years up to and including October 2007. Stage I and II oocytes showed a rise, followed by a fall, in frequency over the course of any year. The sum of the frequencies of stages I and II was low at $0.2 \pm 0.23$ (mean $\pm \mathrm{SD}, \mathrm{n}=16$ ) between June and August, abruptly increased in September to a high of $0.7 \pm 0.22(n=24)$, which lasted for 9 months until the following May, and then decreased again from June. Stage III showed a low frequency throughout the year, with a mean of $0.2 \pm 0.13$ $(n=40)$. No frequency fluctuation pattern was observed for this stage. Late vitellogenic oocytes, in stage IV, were found mainly between June and September, showing a mean frequency of $0.3 \pm 0.21(n=21)$. Frequency peaks in stage IV oocytes in each year were recorded in July of 2003 and 2004, June of 2005 and 2006, and August 2007, with minimum and maximum frequencies of 0.3 and 0.8 in 2003 and 2007, respectively. Fully mature oocytes, in stage V, were observed from June to September, and were abundant in July and August at an average frequency of $0.3 \pm 0.20(n=11)$. Stage $V$ oocyte levels peaked in August 2003, July 2004, July 2005, August
2006, and June 2007, with a mean frequency of $0.5 \pm$ $0.14(\mathrm{n}=5)$. Generally, stage $\mathrm{V}$ oocytes tended to peak in frequency 1-2 months after the peak in stage IV oocytes, with fluctuation in each year.

In males, stages I and II were observed between April and December, with fluctuation in each year, throughout the entire study period (Fig. 5). The sum of the relative frequencies of these stages peaked every June between 2004 and 2007, but in 2003 the frequency peak was observed in November. However, only small numbers of spermaries were found between October and December 2003: 11 in October, 3 in November, and 30 in December. Thus, if the data from October to December 2003 are ignored, stage I and II spermaries showed the highest frequency in June, as occurred from 2004 to 2007. The mean frequency of stage I and II spermaries was notably elevated, at $0.7 \pm 0.25(\mathrm{n}=5)$, every June from 2004 to 2007 , but from July of each year the frequency sharply decreased, to a mean of $0.1 \pm 0.12(n=14)$. Stage III spermaries were usually apparent during the entire period when male colonies were present, but were particularly abundant from July to October, with a mean frequency of 

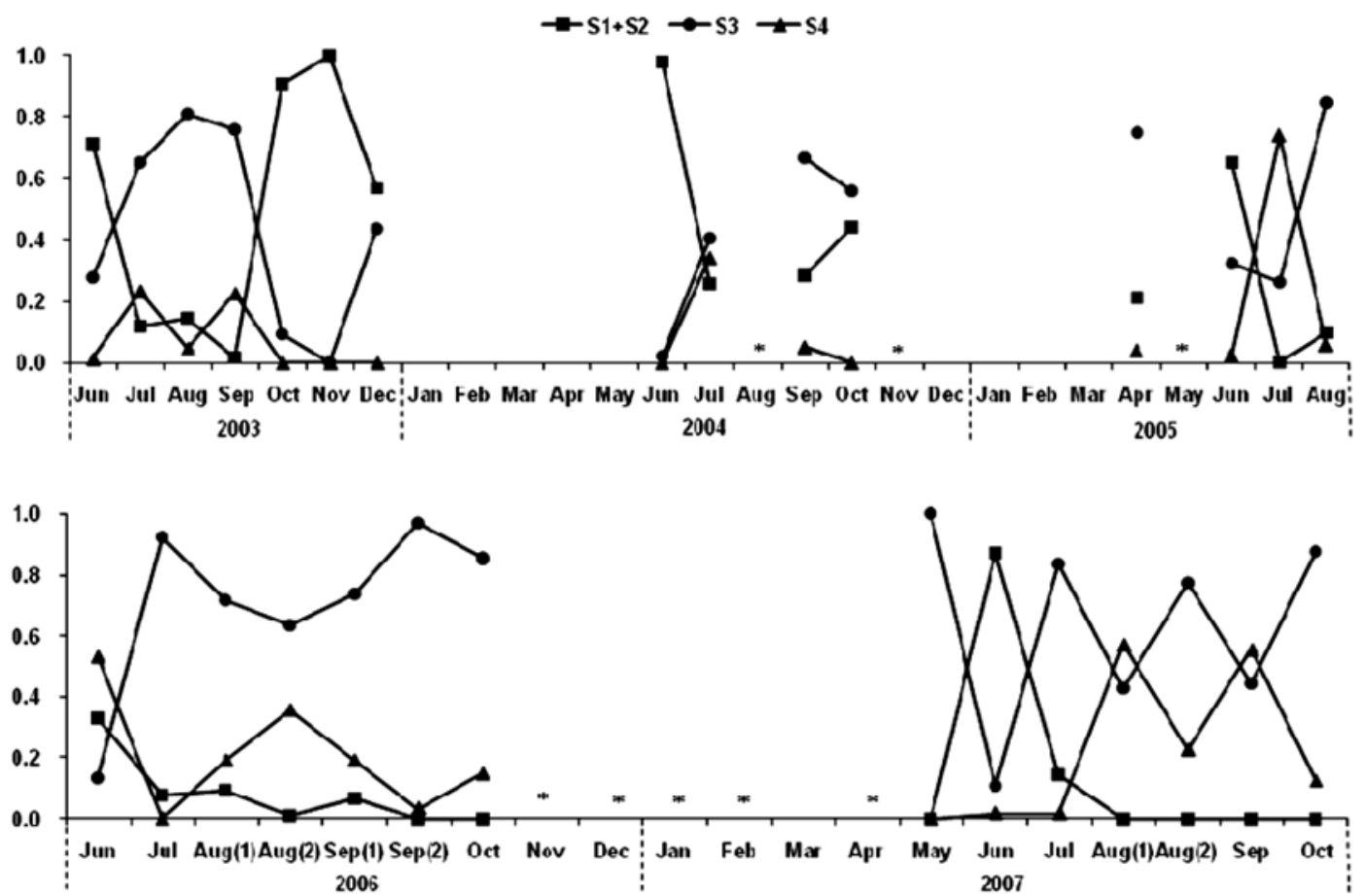

Fig. 5 Monthly frequency of each spermatogenic stage from June 2003 to October 2007 (n=1730 speramries). S1 stage I spermaries, $S 2$ stage II spermaries, $S 3$ stage III spermaries, $S 4$ stage IV spermaries, * month with no collection

$0.7 \pm 0.23(n=20)$. Mature spermaries, in stage IV, were found between June and October, with a mean frequency of $0.3 \pm 0.20(n=15)$. Stage IV spermaries displayed distinct rise and fall patterns, suggesting that reproductive events were underway. In July and September 2003, the frequency of stage IV spermaries peaked, and then dropped to zero. Similar patterns were also evident in 2004 and 2005, with peaks in July followed by rapid declines. Such a rise and fall pattern was recorded twice in 2006, with peaks in June and late August. Also, an additional small peak was observed, together with a high frequency of stage III spermaries, in October 2006, but the number of spermaries rapidly declined from September, suggesting the termination of reproductive events. Rise-and-fall patterns were also noted between August and September 2007.

\section{Spawning of gametes (inferred and observed spawning} events). An actual spawning event was observed on September 3, 2006, in the field, and no embryos or planulae were found in histological sections or dissected colonies, suggesting that broadcast spawning is the reproductive mode of S. gracillimum.
In 2003, the number of mature oocytes (stage V) and the total number of oocytes fell abruptly between August and September (Fig. 6). Mature spermaries were observed only from July to September, and the number of spermaries declined between August and October (Fig. 7). Thus, it is reasonable to infer that a spawning event may have occurred between August and September 2003. In 2004, mature oocytes and spermaries were not found after September, and the numbers of oocytes and spermaries decreased from September, suggesting that spawning occurred in September. In 2005, the numbers of mature oocytes and spermaries fell rapidly between July and August, indicative of the spawning of gametes. However, the total numbers of oocytes and spermaries did not decrease, and oocytes of stage IV and spermaries of stage III were abundant, suggesting an additional spawning event in September even though sampling was not performed. The actual spawning occurred in the field at 10 a.m. on September 3, 2006, 4 days before the full moon, and several potential spawning events might be inferred from decreases in mature gametes between the middle of August and the end of September. Thus, declines in both 

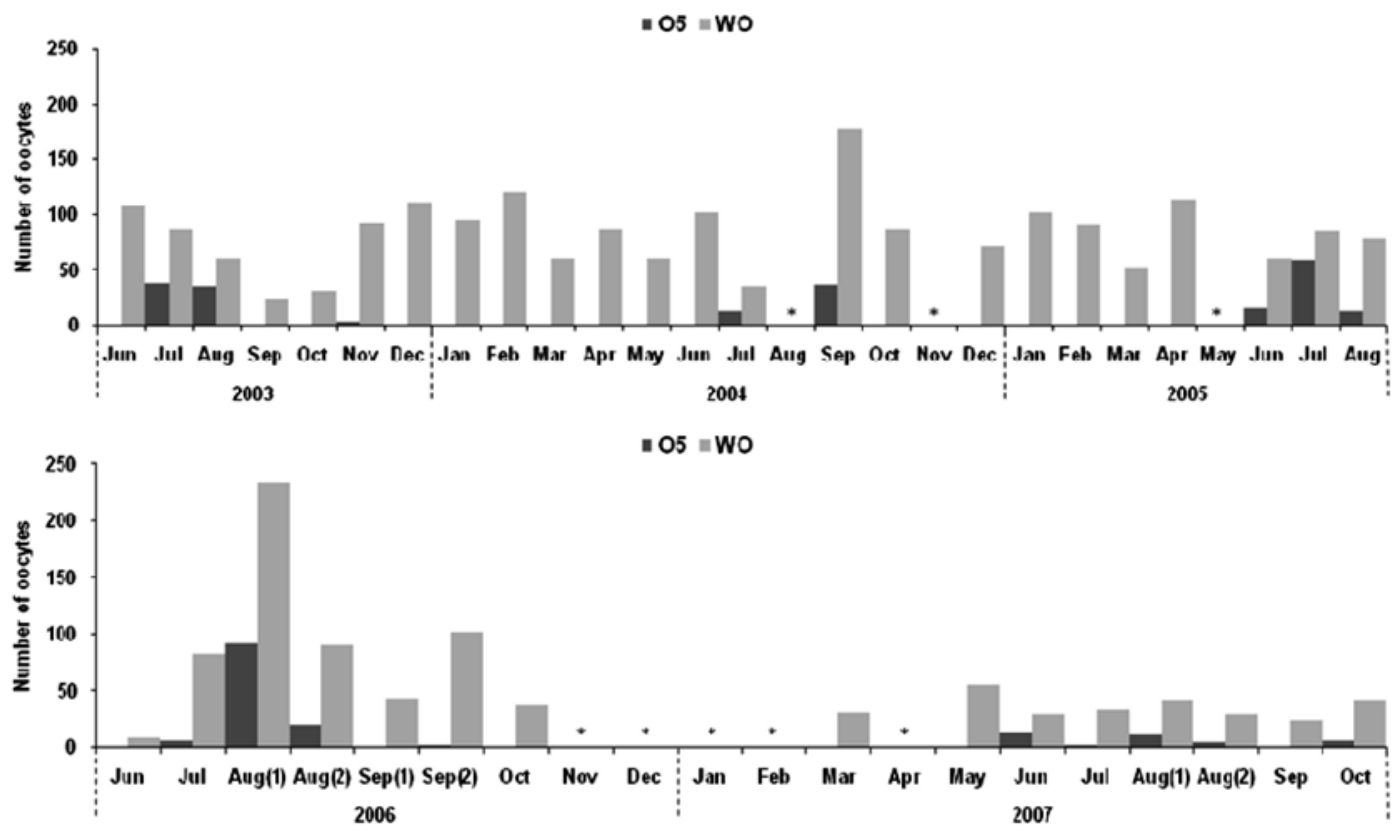

Fig. 6 Total number of mature and entire oocytes from June 2003 to October 2007. O5 stage V oocytes, WO whole oocytes, * month with no collection
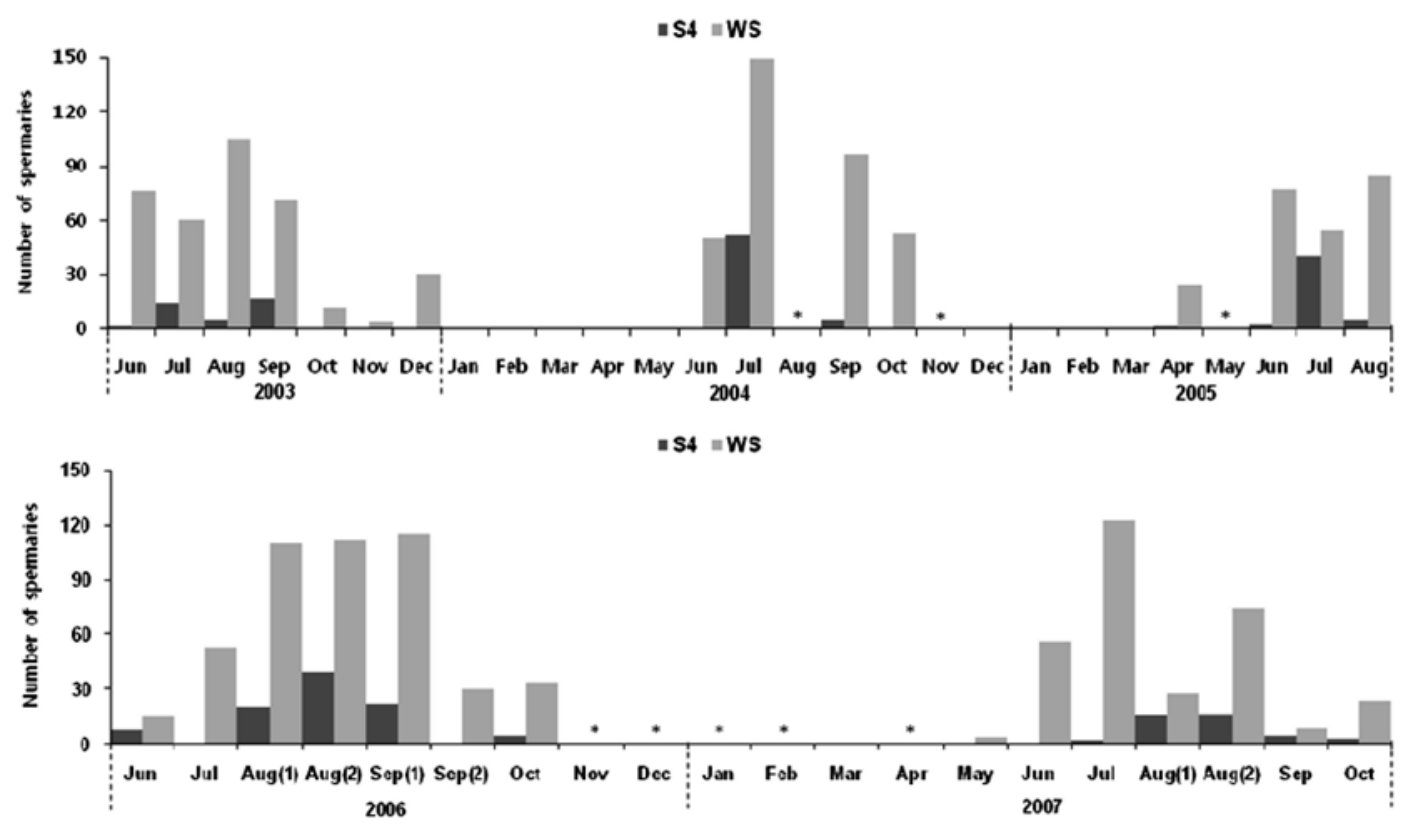

Fig. 7 Total number of mature and entire spermaries from June 2003 to October 2007. S4 stage IV spermaries, WS whole spermaries, * month with no collection 
the number of mature gametes and in the total number of gametes indicated that spawning might have occurred between the end of August (from 1 day after the full moon) to the middle of September (to 1 day before the new moon), in 2007.

\section{Discussion}

The sexual reproductive pattern of the genus Scleronephthya has been identified for the first time in the present study, which established that $S$. gracillimum is a gonochoric broadcaster. To date, very little information on sexual reproduction in the family Nephtheidae has been available, compared to that for other soft corals in the families Alcyoniidae and Xeniidae (Table 1). Gonochorism is known to be the dominant reproductive pattern in soft corals and also in most gorgonians (Grigg 1977; Benayahu et al. 1990; Brazaeu and Lasker 1990; Benayahu 1991; Achituv et al. 1992; Zeevi and Benayahu 1999; Lasker et al. 1996; Schleyer et al. 2004; Orejas et al. 2007; Seo et al. 2008). Whereas hermaphroditism is observed in several species of Alcyoniidae and Xeniidae, only gonochorism is found in Nephtheidae (Sebens 1983; Farrant 1986; Benayahu et al. 1990; Benayahu 1991; Dahan and Benayahu 1997; Choi and Song 2007; Hwang and Song 2007).

In soft corals, sexuality varies according to geographical region. For example, Heteroxenia elizabethae is a gonochoric coral in the Great Barrier Reef, Australia, but is hermaphroditic in the Red Sea. Also, Sarcophyton glaucum shows a low level of hermaphroditism in South Africa, but gonochorism in the Red Sea (Benayahu et al. 1990; Schleyer et al. 2004). The distribution of $S$. gracillimum is fairly wide, from tropical to temperate regions (Song 1976, researcher's observation), which suggests that the sexuality of this species may differ geographically.

To optimize fertilization, and consequently to increase the success of reproduction in broadcasting species, spawning events usually occur synchronously (Benayahu and Loya 1986; Harrison and Wallace 1990; Kapela and Lasker 1999; Schleyer et al. 2004). Especially, reefbuilding corals show a high synchrony of spawning epi- sodes, termed mass spawning, in the Indo-Pacific and Great Barrier Reef regions (Harrison et al. 1984; Babcock et al. 1986: Alino and Coll 1989). During mass spawning, vast numbers of colonies of many species release huge quantities of eggs and sperm over just 1 night. However, temperate corals have a tendency to exhibit a somewhat low level of synchrony in spawning, and display prolonged gametogenesis, whereas spawning events in tropical corals are synchronous (Benayahu 1991; Ben-DavidZaslow et al. 1999; Cordes et al. 2001). S. gracillimum contained mature gametes continuously during the months of summer and early fall, and gametes of different developmental stages were observed together within the same polyp during reproductive periods. These observations suggest relatively asynchronous spawning in our study population, perhaps reflecting the continuous release of gametes. Dendronephthya suensoni and Anthoplexaura dimorpha (respectively a soft coral and a gorgonian) are sympatric with $S$. gracillimum, and show similar spawning patterns during reproductive periods (Choi and Song 2007; Seo et al. 2008). Also, Dendronephthya gigantea, another sympatric species, released planulae continuously from summer to early fall (Hwang and Song 2007).

Thus, corals with asynchronous spawning need to employ a supplementary strategy to increase the possible low level of fertilization resulting from asynchrony. Control of sperm density may efficiently optimize fertilization rate, and sperm density can be affected both by dilution and the distance between female and male colonies. Actual spawning of $S$. gracillimum was observed in the field when the current was weak, and spawning also occurs during periods of slow current in other corals; this minimizes dilution of sperm in water (Kapela and Lasker 1999; Neves and Pires 2002; Penland et al. 2004). In the natural habitat, the colonies of $S$. gracillimum completely cover the surface of the rock, thus prohibiting establishment of other coral species. This high population density in a restricted space may result from asexual reproduction, which may increase the frequency of fertilization, as has been noted in another broadcast-spawning gorgonian, Plexaura kuna (Coffroth and Lasker 1998). However, detailed enumeration of female and male colony numbers in the clonal population is necessary for further study of 
the reproductive strategy of $S$. gracillimum.

The spawning time of $S$. gracillimum approximately coincides with the full moon, occurring 4 days before a full moon in 2006 and in the interval 1 day after full moon to 1 day before the new moon in 2007, which is in line with the behavior of other spawning corals (Harrison et al. 1984; Schleyer et al. 2004; Carroll et al. 2006). However, it is unclear why $S$. gracillimum spawned eggs in the morning on September 3, 2006, as most other spawning corals release eggs and sperm after sunset (Harrison et al. 1984; Lasker et al. 1996; Dahan and Benayahu 1997; Ryland and Westphalen 2004).

The pattern of gonadal formation and arrangement in S. gracillimum is similar to those of other soft corals (Benayahu 1991; Cordes et al. 2001; McFadden and Hochberg 2003; Hwang and Song 2007). Gametes are produced in the mesenteries, and enter the gastrovascular cavity but remain attached to the mesenteries by pedicles. After migration into the cavity, gametes rapidly mature, and the connections between gametes and mesenteries are eliminated as the gametes grow.

The gametogenic cycle was seasonal, and a difference between female and male colonies was apparent, with biorhythms of 12 and 5-7 months respectively. Oocytes developed throughout the year, whereas spermaries formed only during a particular interval that was principally summer-to-fall (June to October) in S. gracillimum. The cycle of gonadal development was thus similar to that of other corals, with a short period of spermatogenesis compared to that of oogenesis (Goldberg and Hamilton 1974; Benayahu and Loya 1984; Alino and Coll 1989; Brazaeu and Lasker 1990; Harii et al. 2001), although spermaries and oocytes are present together all year round in some soft corals (Kruger et al. 1998; Fan et al. 2005). Oogenesis usually takes over 1 year, and the duration varies among soft corals and with respect to geographical region in the same species. For example, oogenesis takes 11-12 months in Parerythropodium $f$. fulvum, but 18-24 months in Sinularia humesi, S. leptoclados, S. mayi, and Litophyton arboreum. In $S$. glaucum, oogenesis requires 16-18 months in Africa and 22-23 months in the Red Sea. All of Lobophytum paciflorum, D. gigantea, and D. suensoni require 12 months for oogenesis (Benayahu et al. 1990; Schleyer et al. 2004; Fan et al. 2005; Choi and
Song 2007; Hwang and Song 2007). However, no relationship between duration of gonadal development and reproductive mode is apparent.

In temperate regions, sexual reproduction, including gametogenesis and spawning, is directly correlated with seasonal factors such as seawater temperature (Harii et al. 2001; Neves and Pires 2002; Vermeiji et al. 2004). The monthly mean diameter of oocytes and spermaries in S. gracillimum increased and decreased in line with fluctuations in seawater temperature throughout our entire study period (Fig. 8). Especially, spermaries were observed only during the warmer seasons, and mature gametes were found only after elevation of seawater temperature to $19-21^{\circ} \mathrm{C}$ in June and July. Actual spawning event occurred, and others may have taken place, when seawater temperature attained an annual peak between August and September. In the sympatric soft corals $D$. gigantea, D. suensoni, and A. dimorpha, a similar reproductive cycle and release pattern of planulae or gametes over the same period correlated with rises and falls in seawater temperature (Choi and Song 2007; Hwang and Song 2007; Seo et al. 2008). Also, the survival and settlement of planulae were enhanced in warmer water, resulting in increased reproductive success (Ben-DavidZaslow and Benayahu 1996; Nozawa and Harrison 2000; Fan et al. 2005)

In addition, $S$. gracillimum is an azooxanthellate coral which requires food resources for survival, growth, and reproduction, and thus feeds on phyto- and zooplankton in water (Fabricius et al. 1995a, b). Acabaria biserialis, the azooxanthellate gorgonian of the Red Sea, released planulae after an algal bloom, which suggests that planula survival is increased by such episodes (Zeevi and Benayahu 1999). Major and minor algal blooms occurred in May and September during reproductive periods at our study site (Choa and Lee 2000). These blooms may form a direct nutrient resource encouraging gametogenesis in adult colonies of $S$. gracillimum, and also facilitating survival and growth of offspring.

\section{Conclusion}

The sexual reproductive pattern of Scleronephthya 

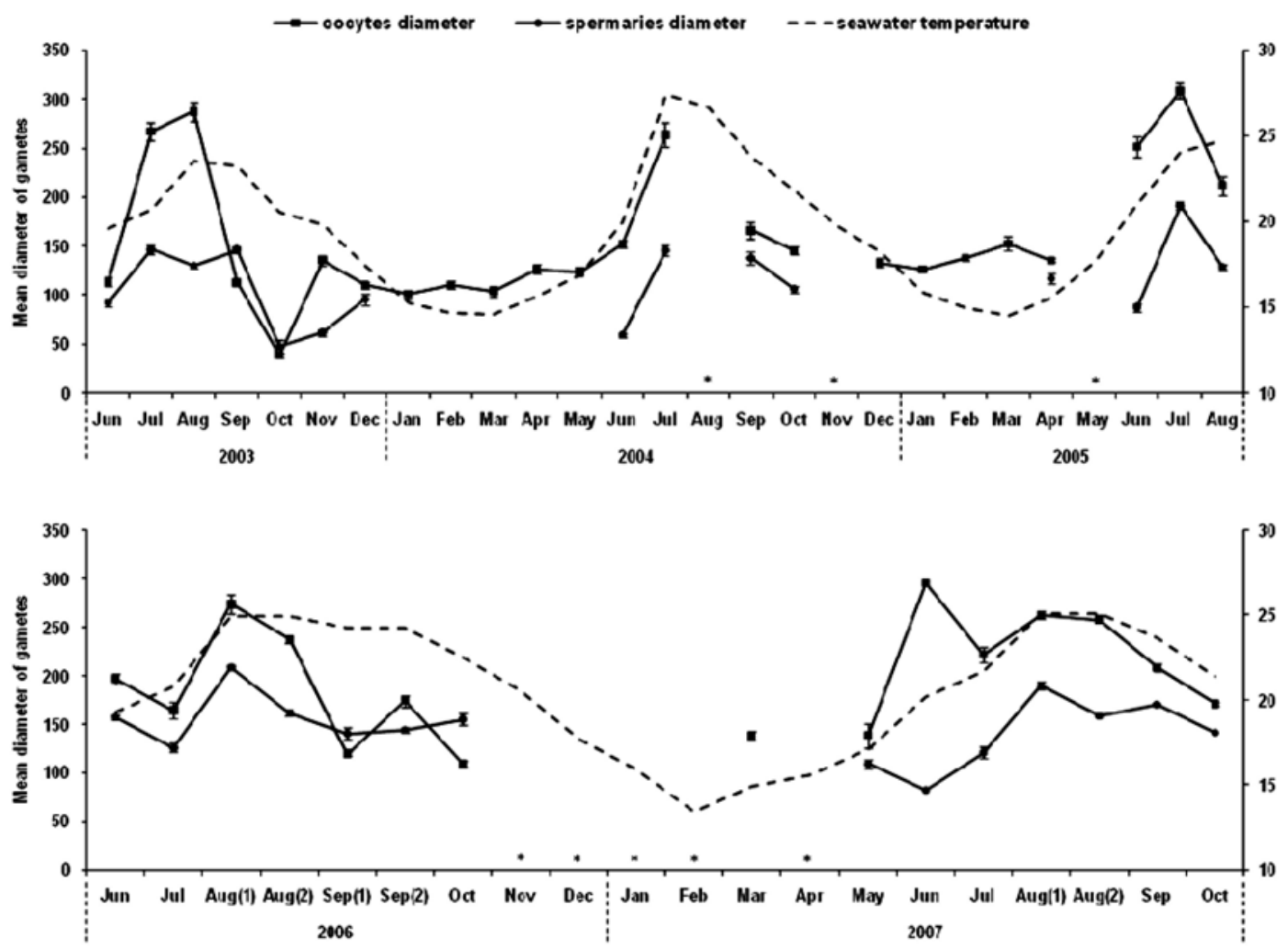

Fig. 8 Monthly mean diameter of oocytes and spermaries according to the seawater temperature (error bar $=S D)$. * month with no collection

gracillimum has been identified for the first time in the present study, focused in sexuality, reproductive mode, gametogenesis, and the reproductive cycle.

- Scleronephthya gracillimum is a gonochoric broadcaster, with the sex ratio of 1:1.

- The oogenic cycle is longer than the spermatogenic cycle, with biorhythms of 12 and 5-7 months respectively.

- Gametogenesis and spawning is related to seasonal factors such as seawater temperature and algal blooms.

- Spawning approximately occurs around the time of full moon.

\section{Acknowledgements}

This research was supported by a grant from Sustainable Conservation and Rehabilitation of Coral Resources in Korea Program Funded by Ministry of Land, Transport and Maritime Affairs of Korean Government. We would like to gratefully thank Yeon Kyu Jung and Digital Eco Photo Club (DEPC) for providing photo of spawning. We also acknowledge HE Song, HN Kim, and JJ Park for their help in the experiment.

\section{References}

Achituv Y, Benayahu Y, Hanania J (1992) Planulae brooding and acquisition of zooxanthellae in Xenia macrospiculata (Cnidaria: Octocorallia). Helgo Meeresunters 46: 301310

Alino PM, Coll JC (1989) Observations of the synchronized mass spawning and post settlement activity of octocorals on the Great Barrier Reef, Australia: biological aspects. Bull Mar Sci 45: 697-707

Babcock RC, Bull GD, Harrison PL, Heyward AJ, Oliver JK, Wallace CC, Willis BL (1986) Synchronous spawning of 105 scleractinian coral species on the Great Barrier Reef. Mar Biol 90: 379-394 
Ben-David-Zaslow R, Benayahu Y (1996) Longevity, competence and energetic content in planulae of the soft coral Heteroxenia fuscescnens. J Exp Mar Biol Ecol 206: 5568

Ben-David-Zaslow R, Henning G, Hofmann DK, Benayahu Y (1999) Reproduction in the Red Sea soft coral Heteroxenia fuscescens: seasonality and long-term record (1991 to 1997). Mar Biol 133: 553-559

Benayahu Y (1991) Reproduction and developmental pathways of Red Sea Xeniidae (Octocorallia, Alcyonacea). Hydrobiologia 216/217: 125-130

Benayahu Y, Loya Y (1984) Life history studies on the Red Sea soft coral Xenia macrospiculata Gohar, 1940. I. Annual dynamics of gonadal development. Biol Bull Mar Biol Lab Woods Hole 166: 32-43

Benayahu Y, Loya Y (1986) Sexual reproduction of a soft coral: synchronous and brief annual spawning of Sarcophyton glaucum (Quoy \& Gaimard, 1833). Biol Bull 170: 32-42

Benayahu Y, Weil D, Kleinman M (1990) Radiation of broadcasting and brooding patterns in coral reef alcyonaceans. Adv Invertebr Reprod 5: 323-328

Brazaeu DA, Lasker HR (1990) Sexual reproduction and external brooding by the Caribbean gorgonian Briareum asbestinum. Mar Biol 104: 465-474

Carroll A, Harrison P, Adjeroud M (2006) Sexual reproduction of Acropora reef corals at Moorea, French Polynesia. Coral Reefs 25: 93-97

Choa JH, Lee JB (2000) Bioecological characteristics of coral habitats around Moonsom, Cheju Island, Korea. I. Environment properties and community structures of phytoplankton. J Korean Soc Oceanogr 5: 59-69

Choi EJ, Song JI (2007) Reproductive biology of the temperate soft coral Dendronephthya suensoni (Alcyonacea: Nephtheidae). Integ Biosci 11: 215-225

Coffroth MA, Lasker HR (1998) Larval paternity and male reproductive success of a broadcast-spawning gorgonian, Plexaura kuna. Mar Biol 131: 329-337

Cordes EE, Nybakken JW, VanDykhuizen G(2001) Reproduction and growth of Anthomastus ritteri (Octocorallia: Alcyonacea) from Monterey Bay, California, USA. Mar Biol 138: 491-501

Dahan M, Benayahu Y (1997) Reproduction of Dendronephthya hemprichi (Cnidaria: Octocorallia): year-round spawning in an azooxanthellate soft coral. Mar Biol 129: 573-579

Fabricius KE, Benayahu Y, Genin A (1995a) Herbivory in asymbiotic soft corals. Science 268: 90-92

Fabricius KE, Genin A, Benayahu Y (1995b) Flow-dependent herbivory and growth in zooxanthellae-free soft corals. Limnol Oceanogr 40: 1290-1301

Fabricius KE, Alderslade P (2001) Soft corals and sea fans: a comprehensive guide to the tropical shallow water genera of the central-west Pacific, the Indian Ocean and the Red Sea. Australian Institute of Marine Science, Townsville, pp 110-111

Fan TY, Chou YH, Dai CF (2005) Sexual reproduction of the alcyonacean coral Lobophytum pauciflorum in southern Taiwan. Bull Mar Sci 76: 143-154

Farrant PA (1986) Gonad development and the planuale of the temperate Australian soft coral Capnella gaboensis. Mar Biol 92: 381-392

Goldberg W, Hamilton R (1974) The sexual cycle in Plexaura homomalla. In: Bayer FM, Wenheiner AJ (eds) Prostaglandins from Plexaura homomalla: ecology, utilization and conservation of a medical marine resource. University of Florida Press, Coral Gables, pp 58-61

Grigg RW (1977) Population dynamics of two gorgonian corals. Ecology 58: 278-290

Harii S, Omori M, Yamakawa H, Koike Y (2001) Sexual reproduction and larval settlement of the zooxanthellate coral Alveopora japonica Eguchi at high latitudes. Coral Reefs 20: 19-23

Harrison PL, Babcock RC, Bull GD, Oliver JK, Wallace CC, Willis BL (1984) Mass spawning in tropical reef corals. Science 223: 1186-1189

Harrison PL, Wallace CC (1990) Reproduction, dispersal and recruitment of scleractinian corals. In: Dubinsky Z (ed) Ecosystems of the world, vol 25, Coral reefs. Elsevier, Amsterdam, pp 133-207

Hwang SJ, Song JI (2007) Reproductive biology and larval development of the temperate soft Dendronephthya gigantea (Alcyonacea: Nephtheidae). Mar Biol 152: 273284

Kapela W, Lasker HR (1999) Size-dependent reproduction in the Caribbean gorgonian Pseudoplexaura porosa. Mar Biol 135: 107-114

Kruger A, Schleyer MH, Benayahu Y (1998) Reproduction in Anthelia glauca (Octocorallia: Xeniidae). I. Gametogenesis and larval brooding. Mar Biol 131: 423-432

Lasker HR, Kim K, Coffroth MA (1996) Reproductive and genetic variation among Caribbean gorgonians: the differentiation of Plexaura kuna, new species. Bull Mar Sci 58: 277-288

McFadden CS, Donahue R, Hadland BK, Weston R (2001) A molecular phylogenetic analysis of reproductive trait 
evolution in the soft coral genus Alcyonium. Evolution 55: 54-67

McFadden CS, Hochberg FG (2003) Biology and taxonomy of encrusting alcyoniid soft corals in the northeastern Pacific Ocean with descriptions of two new genera (Cnidaria, Anthozoa, Octocorallia). Invertebr Biol 122: 93-113

Neves EG, Pires DO (2002) Sexual reproduction of Brazilian coral Mussismilia hispida (Verrill, 1902). Coral Reefs 21: $161-168$

Nozawa Y, Harrison PL (2000) Larval settlement patterns, dispersal potential, and the effect of temperature on settlement of larvae of the reef coral, Platygyra daedalea, from the Great Barrier Reef. Proc 9th Int Coral Reef Symp 1: 409-415

Orejas C, Gili JM, López-González PJ, Hasemann C, Arntz WE (2007) Reproduction patterns of four Antarctic octocorals in the Weddell Sea: an inter-specific, shape, and latitudinal comparison. Mar Biol 150: 551-563

Penland L, Kloulechad J, Idip D, van Woesik R (2004) Coral spawning in the western Pacific Ocean is related to solar insolation: evidence of multiple spawning events in Palau. Coral Reefs 23: 133-140

Ryland JS, Westphalen D (2004) The reproductive biology of Parazoanthus parasiticus (Hexacorallia: Zoanthidea) in Bermuda. Hydrobiologia 530/531: 411-419

Schleyer MH, Kruger A, Benayahu Y (2004) Reproduction and the unusual condition of hermaphroditism in Sarcophyton glaucum (Octocorallia, Alcyoniidae) in KwaZulu-Natal, South Africa. Hydrobiologia 530/531: 399-409

Sebens KP (1983) The larval and juvenile ecology of the temperate octocoral Alcyonium siderium Verrill. I. Substratum selection by benthic larvae. J Exp Mar Biol Ecol 71: 73-89

Seo SY, Hwang SJ, Song JI (2008) Sexual reproduction of Anthoplexaura dimorpha (Gorgonacea: Octocorallia) from Munseom, Jejudo Island, Korea. Ani Cell Sys 12: 231240

Song JI (1976) A study on the classification of the Korean Anthozoa 2. Alcyonacea. Korean J Zool 19: 51-62

Vermeij MJA, Sampayo E, Bröker K, Bak RPM (2004) The reproductive biology of closely related coral species: gametogenesis in Madracis from the southern Caribbean. Coral Reefs 23: 206-214

Zeevi D, Benayahu Y (1999) The gorgonian coral Acabaria biserialis: life history of a successful colonizer of artificial substrata. Mar Biol 135: 473-481

Received: 30 September 2009

Accepted: 23 October 2009

C Japanese Coral Reef Society 